\title{
Iron and Ferroptosis as Therapeutic Targets in Alzheimer's Disease
}

\author{
Andrew Gleason ${ }^{1} \cdot$ Ashley I. Bush ${ }^{1}$ \\ Accepted: 17 October 2020 / Published online: 27 October 2020 \\ (C) The American Society for Experimental NeuroTherapeutics, Inc. 2020
}

\begin{abstract}
Alzheimer's disease (AD), one of the most common neurodegenerative diseases worldwide, has a devastating personal, familial, and societal impact. In spite of profound investment and effort, numerous clinical trials targeting amyloid- $\beta$, which is thought to have a causative role in the disease, have not yielded any clinically meaningful success to date. Iron is an essential cofactor in many physiological processes in the brain. An extensive body of work links iron dyshomeostasis with multiple aspects of the pathophysiology of AD. In particular, regional iron load appears to be a risk factor for more rapid cognitive decline. Existing ironchelating agents have been in use for decades for other indications, and there are preliminary data that some of these could be effective in AD. Many novel iron-chelating compounds are under development, some with in vivo data showing potential Alzheimer's disease-modifying properties. This heretofore underexplored therapeutic class has considerable promise and could yield much-needed agents that slow neurodegeneration in AD.
\end{abstract}

Key Words Alzheimer's disease · therapeutics · treatment · iron · chelation $\cdot$ ferroptosis

\section{Introduction}

Around 50 million people have dementia worldwide, with nearly 10 million new cases each year. Dementia is one of the leading causes of disability among older people and was the fifth leading global cause of death in 2016. Alzheimer's disease $(\mathrm{AD})$, the most common type of dementia, accounts for about two thirds of cases [1].

Pathologically, AD is characterized by cerebral atrophy, extracellular deposition of amyloid- $\beta$ peptide in senile plaques, intraneuronal accumulation of hyperphosphorylated tau in neurofibrillary tangles, chronic inflammation, oxidative stress, and loss of neurons and synapses [2]. The predominant pathophysiological model for $\mathrm{AD}$ is the amyloid cascade hypothesis, first proposed in 1992 [3]. This posits that the causative and initial pathological event in $\mathrm{AD}$ is deposition of amyloid- $\beta$, which forms senile plaques. The corollary of the

Supplementary Information The online version contains supplementary material available at https://doi.org/10.1007/s13311-02000954-y.

Ashley I. Bush

ashley.bush@florey.edu.au

1 Florey Institute of Neuroscience and Mental Health, University of Melbourne, 30 Royal Parade, Parkville, Victoria 3052, Australia amyloid cascade hypothesis is that anti-amyloid- $\beta$ therapies should modify the course of AD.

Numerous anti-amyloid therapies, such as $\beta$-secretase converting enzyme inhibitors and anti-amyloid- $\beta$ monoclonal antibodies, lower amyloid in the brain and cerebrospinal fluid, but none these drugs have been shown to delay disease progression [4]. To date, several dozen phase 3 trials have failed to meet primary endpoints. Recently, studies of aducanumab, a monoclonal antibody with promising initial data, were terminated after a futility analysis only to be revived when further data were analyzed in spite of controversy over these results due to the potential of unblinding $[5,6]$. Some argue that the use of anti-amyloid- $\beta$ therapeutics in the symptomatic stage of AD may be too late. This hypothesis is being tested in ongoing trials in presymptomatic amyloid-positive individuals at risk of sporadic AD [7] and in people with mutations in genes associated with dominantly inherited $\mathrm{AD}$ [8], but the multiple failures of prior amyloid- $\beta$-lowering agents does not bode well for the outcome of these studies. Furthermore, it is well-established that amyloid- $\beta$ is often present in healthy older brains [9]. These data shed mounting doubt on the validity of the amyloid cascade hypothesis and whether amyloid-lowering therapeutics have any prospect of clinically meaningful efficacy. New aspects of neurodegeneration in $\mathrm{AD}$ need to be explored in order to pave the way to diseasemodifying therapeutics. 


\section{Iron and Oxidative Stress in the Brain}

Of particular interest is the potential role of ferroptosis, a form of nonapoptotic programmed cell death characterized by irondependent accumulation of lipid hydroperoxides to lethal levels [10], which has been implicated in a number of neurodegenerative disorders $[11,12]$.

Iron is an essential cofactor for many physiological functions [13]. The ability to easily gain or lose electrons makes it well suited for metabolic processes, such as the transport and activation of small molecules and electron transfer [13, 14]. The vast majority of the $5 \mathrm{~g}$ or so of iron in the body is found in hemoglobin and myoglobin, as well as the storage proteins ferritin and hemosiderin. Only a few hundred milligrams are involved in critical enzymatic processes which capitalize on iron's variable coordination chemistry, permitting it to exist in different oxidation states, including $0,+2,+3,+4$, and +6 . Ferrous $\left(\mathrm{Fe}^{2+}\right)$ and ferric $\left(\mathrm{Fe}^{3+}\right)$ iron and are the most common in biological systems [13].

The brain has a high demand for adenosine triphosphate (ATP) to maintain membrane ion gradients, synaptic transmission, and axonal transport. Iron is part of cytochromes a, b, and $\mathrm{c}$, cytochrome oxidase, and the iron-sulfur complexes of the oxidative chain, making it essential for ATP production [15]. Iron is also involved in the synthesis of neurotransmitters, as well as lipids and cholesterol, which are substrates for myelin synthesis [14, 16-18]. Although iron is essential for normal brain functioning, it is toxic in the case of overload or dyshomeostasis, which can cause neurodegeneration by disrupting mitochondrial function, depleting ATP, and inducing oxidative damage and chronic inflammation, resulting in damage to lipids, proteins, and DNA [14, 15, 19-22]. Cognition, motor function, dopamine-related functions, and myelinogenesis are commonly affected in CNS iron dysregulation [15].

The ability of iron to undergo oxidation-reduction allows it to convert hydrogen peroxide to toxic free radicals, leading to oxidative stress and cell death via the Fenton reaction, first described in 1894 [14, 23, 24]. When free iron donates an electron to hydrogen peroxide, a hydroxyl radical is produced, which is one of the most reactive free radical species known: $\mathrm{Fe}^{2+}+\mathrm{H}_{2} \mathrm{O}_{2} \rightarrow \mathrm{Fe}^{3+}+\mathrm{OH}+\mathrm{OH}^{-}[14,24]$. Iron-induced oxidative stress causes a positive-feedback loop of additional iron release from ferritin, heme proteins, and iron-sulfur clusters [14]. Free iron is more likely to exchange electrons with nearby molecules than when protein-bound, leading to further free radical production [14]. When free radicals are generated near membrane phospholipids, they initiate peroxidation of polyunsaturated fatty acids, leading to production of lipid hydroperoxides which break down to form lipid-derived $\alpha, \beta$-unsaturated 4-hydroxyaldehydes $[25,26]$. Free radical-induced modifications to proteins leads to the addition of reactive carbonyl functional groups, generated from lipid peroxidation, glycation, and amino acid oxidation [27, 28].

Although most models of iron-mediated neuronal injury involve Fenton-mediated hydroxyl radicals, an alternative model posits that depletion of reduced glutathione decreases activity of monothiol glutaredoxins and decreased incorporation of iron into target metalloproteins. This leads to an increase in available iron in the cell, which is diverted to the chaperone poly(rC)-binding protein 1 and hypoxia-inducible factor prolyl hydroxylases (HIF PHDs) in the cytoplasm and nucleus. Increased HIF PHD1 activity results in enhanced transcription of activating transcription factor 4-dependent pro-death genes and induction of ferroptotic death [29].

It is unsurprising that free iron levels are tightly regulated. Iron is generally bound to chaperone proteins in order to control its reactivity, restricting it to specific locations where it cycles between reduced $\left(\mathrm{Fe}^{2+}\right)$ and oxidized $\left(\mathrm{Fe}^{3+}\right)$ states as part of physiological processes [30, 31]. In the plasma, iron exists primarily as $\mathrm{Fe}^{3+}$ bound to transferrin [14]. The main protective strategy to prevent iron overload in the brain is selective transport systems on the blood-brain barrier [32]. Iron-transferrin complexes circulating in the blood cross the blood-brain barrier via endocytosis mediated by the transferrin receptor (TfR) on the surface of capillary endothelial cells [32]. Iron is then transported from the basolateral membrane of endothelial cells to the cerebral compartment, where it is available to neurons and glia [14]. Nontransferrin-bound iron can enter via lactoferrin receptors [33]. Intracellular free iron exists in the reduced form $\mathrm{Fe}^{2+}$, which acts as a cofactor for iron-dependent enzymes in the cytosol, mitochondria, and nucleus [32]. Intracellular iron levels are controlled by ironregulatory proteins that bind iron-responsive elements in mRNA [23]. Anti-oxidant defenses inhibit damage caused by free radicals, via the enzymes superoxide dismutase (SOD), catalase (CAT), and glutathione peroxidase (GPx) $[13,14]$, as well as nonenzymatic anti-oxidant substances such as ascorbic acid (vitamin C), alpha-tocopherol (vitamin E), carotenoids, and flavonoids [14].

\section{Brain Iron Is Elevated in Alzheimer's Disease}

Accumulating evidence suggests that iron excess and dyshomeostasis contribute to neurodegeneration in $\mathrm{AD}[12$, 32]. Several of the biological abnormalities seen in $A D$ are consistent with free radical damage from impaired iron homeostasis [34].

Iron elevation was first shown in the brains of people with $\mathrm{AD}$ in 1953 [35]. Elevated brain iron in AD has been confirmed in numerous subsequent studies both post mortem [36-42] and in vivo [36, 38, 42-53]. Iron rises in the brain with aging and may be pathological because it is associated with cognitive decline prior to disease $[54,55]$. Increased iron 
occurs as early as the mild cognitive impairment stage of $\mathrm{AD}$ and contributes to longitudinal outcomes [56, 57]. Iron and ferritin are found within plaques, NFTs, and blood vessels in $\mathrm{AD}$ [42]. Although an increase in brain iron levels may contribute to $\mathrm{AD}$ pathology, it is excessive iron in specific intracellular compartments or regions of the brain, i.e., regional siderosis, that appears to drive neurotoxicity, particularly in the cortex and hippocampus [14, 36, 42, 58, 59].

Several MRI modalities can be used to image iron levels. T2* MRI allows semiquantitative measurement of brain iron, though the results are influenced by differences in crystal structure, unequal clustering of ferritin, and the size of the magnetic particle [60]. Severity of AD pathology correlates with iron accumulation on postmortem T2*-weighted MRI [61]. Quantitative susceptibility mapping (QSM) is more specific than other MRI modalities as a measure of tissue magnetic susceptibility and correlates well with brain iron levels [62]. QSM imaging demonstrated increased brain iron levels in multiple regions of interest in people with $\mathrm{AD}$ compared to controls [63]. QSM also correlates with clinical measures. Higher hippocampal QSM levels predicted accelerated decline in episodic memory, and temporal and frontal QSM levels predicted deteriorating performance on a language task [64]. Magnetic susceptibility in the left caudate also correlated with declining scores on the Mini-Mental State Examination and Montreal Cognitive Assessment in mild and moderate AD [62]. A recent Australian Imaging Biomarker and Lifestyle prospective study found that when brain iron load measured by MRI was compared in normal elderly and mild cognitive impairment (MCI) and $\mathrm{AD}$ subjects, brain iron loading was exaggerated in a manner that correlated with cognitive impairment [65].

Brain iron load also impacts longitudinal AD outcomes [66]. Elevated cerebrospinal fluid (CSF) ferritin, a reporter of brain iron burden $[67,68]$, independently predicted conversion to $\mathrm{AD}$ and was associated with poorer cognition and hippocampal atrophy [69]. CSF ferritin levels are associated with disease progression in prodromal people with high amyloid- $\beta$ pathology determined by CSF $\mathrm{t}$-tau/A $\beta 42$ ratio [70]. High CSF ferritin levels are also associated with accelerated depreciation of CSF $A \beta 1-42$, from threshold preclinical levels to the average level of Alzheimer's subjects, suggesting that iron may facilitate amyloid- $\beta$ deposition, accelerating the process of $\mathrm{AD}$ [71]. Plasma ferritin levels are elevated in cognitively normal amyloid PET-positive older subjects compared to controls with low neocortical amyloid load [72], suggesting that impaired iron mobilization is an early event in $\mathrm{AD}$ pathogenesis [72]. The magnitude of impact of CSF ferritin on $\mathrm{AD}$ outcomes is commensurate with the tau/A $\beta 42$ ratio, previously one of the best CSF diagnostic biomarkers for $\mathrm{AD}$ [73]. CSF ferritin thus appears to be a complementary prognostic biomarker to the t-tau/A $\beta 42$ ratio that predicts near-term disease progression risk [64].
In addition to ferritin, other proteins involved in iron transport correlate with AD symptoms. CSF levels of melanotransferrin, a transferrin homolog that binds iron, are associated with conversion of MCI to AD [74]. Hepcidin is a regulatory protein present in the brain which binds to the iron channel ferroportin, leading to decreased export of cellular iron [75-77]. Serum hepcidin levels are raised in AD and correlate, albeit weakly, with the Clinical Dementia Rating Scale [75]. Although it is possible that the finding of raised serum hepcidin could have been the result of inflammationbased induction of hepatic hepcidin production, values did not correlate with C-reactive protein levels in this cohort, though subjects with levels greater than $5 \mathrm{mg} / 1$ were excluded [75]. In the healthy brain, hepcidin and ferroportin are widely distributed and colocalize in neurons and astrocytes, suggesting a role for these proteins in regulating neuronal iron release. In $\mathrm{AD}$ brains, hepcidin expression is reduced and anatomical distribution is restricted to neuropil, blood vessels, and damaged neurons [76]. Brain ferroportin levels are also reduced in $\mathrm{AD}$, potentially secondary to ischemia, inflammation, neuronal loss, and senile plaque formation [76]. The reason for reduced hepcidin levels in AD brain are less certain, but reduced passage across damaged vascular endothelium is one possibility [29].

Some potential sources of increased brain iron deposits include bleeding, iron-containing macrophages crossing the blood-brain barrier, and dysregulated blood-brain barrier iron transport [78]. Phagocytic cells containing iron are often present in areas of neurodegenerative changes. These cells may have migrated to these regions in order to phagocytose iron, or iron-containing phagocytic cells may enter the central nervous system as part of an inflammatory response [78]. Lysosomal dysfunction may also be a source of increased CNS iron uptake [78].

\section{Amyloid Precursor Protein in Iron Transport and Oxidative Stress}

There is a complex interplay between amyloid- $\beta$, tau, and iron in both physiological and pathological states, which can be used to integrate the role of iron into a modified version of the amyloid cascade hypothesis.

Amyloid- $\beta$ is generated from amyloid precursor protein (APP) [79], a single-pass transmembrane protein with high levels of expression in the brain [80]. APP helps protect cells from iron-catalyzed oxidative stress by loading $\mathrm{Fe}^{3+}$ onto transferrin and stabilizing the iron export channel ferroportin [36]. APP knockout mice have decreased ferroportin levels and increased levels of age-related iron accumulation with concomitant oxidative stress in cortical neurons [36]. APP may thus act to oppose brain iron elevation during normal aging [81]. APP levels are modulated by an iron-responsive 
element (IRE) in the $5^{\prime}$ untranslated region of the APP transcript $[82,83]$. In conditions of high iron, such as Alzheimer's disease, APP translation is increased [84]. Iron regulation of APP mRNA suggests that this could be a target for iron chelators [82]. Intracellular iron chelation increased binding of iron-responsive element-binding protein 1 to the APP IRE, decreasing APP expression [82, 83].

Dysregulation of iron homeostasis is a common effect of mutations in the genes involved in early-onset familial Alzheimer's disease, PSEN1, PSEN2, and APP. PSEN and APP may be involved in regulation of iron homeostasis throughout the aging process [85].

\section{Iron Binds Amyloid and Tau, Promoting Toxicity}

Iron binds amyloid in vitro [86] with an affinity eight times higher than that in transferrin [87] and is elevated in senile plaques [14, 35]. X-ray microscopy techniques at submicron resolution in the APP/PS1 mouse model of AD showed a direct correlation of amyloid plaque morphology with iron as well as evidence for the formation of an iron-amyloid complex [88]. Magnetite iron species was shown in plaques, suggesting aberrant iron redox chemistry [88]. Quantitative susceptibility mapping compared with flutemetamol positron emission tomography (PET) showed local correlation between $\beta$-amyloid plaque and iron deposition in healthy older adults without dementia [89].

Tau, the main component of neurofibrillary tangles, helps mediate iron efflux from cells [90]. High levels of iron colocalize with tau in neurofibrillary tangles [90, 91]. Iron promotes tau hyperphosphorylation by inducing kinases and possibly also by impacting protein phosphatase $2 \mathrm{~A}$ activity [90, 92]. Iron also causes aggregation of hyperphosphorylated tau [93-95] via an iron-binding motif in the tau protein [90].

\section{Amyloid- $\beta$ Plaques Are a Site of Redox Activity, Facilitated by Iron}

Iron causes amyloid- $\beta$ aggregation in vitro [96-98] and promotes $A \beta$ aggregate toxicity [99-101]. The affinity of amyloid- $\beta$ for iron increases following aggregation, and further iron binding leads to additional neuronal cytotoxicity [97, 99-104]. Protein carbonyl groups, markers of oxidative damage to DNA and proteins, are seen in preclinical and established Alzheimer's disease [105, 106].

Amyloid- $\beta$ plaques and neurofibrillary tangles are major sites of redox reactivity, which is catalyzed by iron binding $[30,34,42,87,98]$. In vitro studies show that amyloid- $\beta$ captures and reduces $\mathrm{Fe}^{3+}$ from the ferritin core, leading to intraneuronal $\mathrm{Fe}^{2+}$ elevation $[36,107]$ and production of hydrogen peroxide. Hydroxyl radicals may then contribute to oxidative damage on both the amyloid- $\beta$ peptide and surrounding molecules including proteins, lipids, and nucleic acids, with concomitant disruption of membrane integrity [30]. Oxidation also impairs amyloid- $\beta$ clearance by the low-density lipoprotein receptor-related protein (LRP1) [30]. Elevated levels of $A \beta 1-40$ and $A \beta 1-42$ are associated with increased levels of oxidation products in the AD hippocampus and cortex [108]. Given that iron appears to contribute to amyloid- $\beta$-mediated toxicity, it is possible that ironmodifying therapies may have benefit where other modalities of anti-amyloid- $\beta$ therapeutics have failed.

\section{Iron Overload Impairs Microglia, Increasing Reactive Oxygen Species Production}

Iron overload causes microglia to take on a senescent phenotype with reduced motility and altered surveillance. When confronted with injury, they produce a more sustained inflammatory response with increased reactive oxygen species (ROS) production. It is possible that microglia are pushed to a more pro-inflammatory phenotype by age-related changes [109]. Stimulation of cultured microglia with amyloid- $\beta$ induces an inflammatory phenotype, causing these cells to retain iron, and reduces their phagocytic and chemotactic functioning [110]. Microglia extracted from APP/PS1 mice also have an iron-retentive phenotype with reduced amyloid- $\beta$ phagocytotic ability [110].

\section{Ferroptosis in AD}

Ferroptosis, first described in 2012, is biochemically and morphologically distinct from other forms of cell death such as apoptosis and necrosis and is characterized by iron-dependent accumulation of lipid peroxides [10,11]. Ferroptosis is induced by the small molecule erastin, which inhibits cysteine import via the cystine-glutamate antiporter system Xc-, leading to depletion of glutathione, a tripeptide formed from cysteine, glutamate, and glycine [10]. Glutathione is a substrate for the selenoenzyme glutathione peroxidase 4 (GPX4), which converts potentially toxic lipid hydroperoxides to nontoxic lipid alcohols [111-113]. Morphological features of ferroptosis include small mitochondria with condensed mitochondrial membrane densities, reduction or vanishing of mitochondrial crista, outer mitochondrial membrane rupture, and electron lucent nuclei [114, 115].

Ferritinophagy may play a critical role in the regulation of ferroptosis [116]. When ferroptosis is induced via cysteine depletion, nuclear receptor coactivator 4 mediates the autophagic degradation of ferritin (ferritinophagy), leading to release intracellular free iron [116]. HER2C, a modulator of 
ferritinophagy [116], regulates turnover of FBXL5, which is part of a complex that targets iron regulatory protein 2 for proteasomal degradation and thus appears to play a role in iron metabolism [117]. HERC2 deficiency could induce neurodegeneration by impairing response to increased iron levels, leading to ferritinophagy, release of free iron, and neuronal damage [116].

Erythroid 2-related factor 2 (Nrf2) is a transcription factor that regulates genes involved in the metabolism of glutathione, iron and lipids, and mitochondrial function [118]. Nrf2 may help protect against ferroptosis, and enhancing Nrf2 signalling may hence be neuroprotective [118].

Emerging work suggests that ferroptosis may play a role in $\mathrm{AD}$ pathology. Lipid peroxidation levels are elevated in the brain in $\operatorname{AD}[119,120]$. Mice with a conditional deletion of GPX4 display cognitive impairment and hippocampal degeneration similar to that of $\mathrm{AD}$ with neurodegenerative features of ferroptosis (including lipid peroxidation, extracellular signal-related kinase (ERK) activation, and neuroinflammation), which is ameliorated by a ferroptosis inhibitor [121]. Ferroptosis may exacerbate AD by targeting the hypoxiainducible factor $1 \alpha$ and heme oxygenase-1 pathways [116].

Ferroptosis is modulated by pharmacological perturbation of lipid repair systems involving glutathione and GPX4 [11]. Cell death caused by ferroptosis can be suppressed by iron chelators, lipophilic anti-oxidants, inhibitors of lipid peroxidation, and depletion of polyunsaturated fatty acids [11]. Some ferroptosis inhibitors appear in Table 1 [11].

Studies of therapeutics with potential anti-ferroptosis activity show promise, though there are few data from human studies. Trials of vitamin E supplementation to prevent cognitive decline or treat $\mathrm{AD}$ have produced conflicting results [122]. Donepezil-butylated hydroxytoluene hybrids have been designed as potential anti-AD therapies [123]. Studies of idebenone have shown cognitive improvement in $\mathrm{AD}$, but conclusive evidence for a benefit of sufficient magnitude to be clinically significant is lacking [124-126]. In rat models of $\mathrm{AD}$, vildagliptin modulated $\mathrm{AD}$-associated biochemical changes [127], reduced tau phosphorylation, increased the expression of proteins associated with synaptic plasticity in the hippocampus [128], attenuated amyloid- $\beta$, and improved memory [129]. Linagliptin mitigated cognitive deficits, as well as attenuating amyloid- $\beta$, tau phosphorylation, and neuroinflammation in a 3xTg-AD mouse model [130]. In cultured human neuronal cells, linagliptin alleviated amyloid- $\beta$ induced mitochondrial dysfunction and intracellular ROS generation [131]. Studies of deferoxamine and deferiprone in $\mathrm{AD}$ are discussed below. Baicalein improved cognition decreased amyloid- $\beta$ and prevented tau phosphorylation in AD mouse models [132, 133]. PD-146176 preserved memory, lowered amyloid- $\beta$, decreased tau pathology, and reduced autophagy in a $3 \times$ Tg mouse model of AD [134, 135]. Zileuton improved memory and reduced amyloid- $\beta$ and tau pathology
Table 1 Ferroptosis inhibitors

Lipid peroxidation inhibitors

- Vitamin E

- Deuterated polyunsaturated fatty acids

- Butylated hydroxytoluene

- Butylated hydroxyanisole

- Ferrostatins

- Liproxstatins

- Coenzyme Q10

- Idebenone

- Gliptins (vidagliptin, alogliptin, linagliptin)

Iron depleters

- Deferoxamine

- Cyclipirox

- Deferiprone

Lipoxygenase-induced lipid peroxidation inhibitors

- CDC (cinnamyl-3,4-dihydroxy- $\alpha$-cyanocinnamate)

- Baicalein

- PD-146176

- AA-861

- Zileuton

System Xc- inhibitor blockers

- Cycloheximide

- 2-Mercaptoethanol

Blocker of GPX4 degradation

- Dopamine

Increased selenoproteins

- Selenium

Modified from Stockwell et al. [11]

in $3 \times \operatorname{Tg} \mathrm{AD}$ mice $[136,137]$. A small randomized controlled pilot trial of supra-nutritional sodium selenate in $\mathrm{AD}$ showed that subjects whose CSF selenium concentrations raised with treatment had reduced deterioration on the Mini-Mental Status Examination (MMSE) [138].

\section{Ideal Aspects of Chelators}

There are a number of factors that potentially affect the efficacy and tolerability of iron chelators for AD and other neurodegenerative disorders.

The efficiency with which a chelator binds iron and its transmembrane transport properties appear to be major factors in efficacy [139]. A chelator for AD obviously needs to penetrate the blood-brain barrier. Chelators can remove iron from the site of accumulation directly, or transfer it to other molecules.

Use of nonselective chelators may affect the homeostasis of iron-dependent processes, such as depleting transferrin-bound iron in the plasma, leading to side effects [140,141]. Moderate affinity chelators may be less likely than high-affinity chelators to remove metals from physiological processes [142]. Another strategy is utilizing site- or process-specific chelators, 
such as pro-chelators, which have little affinity for metal ions until they undergo a chemical conversion in response to a specific stimulus [141]. Agents that target disease-specific pathophysiology, such as anti-ferroptotics, may also achieve the aim of modulating a disease process without affecting normal physiology. Given that iron may drive cell death by activating iron-sensing hypoxia-inducible factor prolyl hydroxylases, these could be a target of protection from ferroptosis via iron chelation [29].

\section{Iron Chelators Currently Available}

Iron chelators are currently used clinically for transfusiondependent patients with iron overload and beta thalassemia major, sickle cell anemia, myelodysplasia, and aplastic anemia [143]. They are also used rarely in people with hemochromatosis who are unsuitable for phlebotomy due to severe cardiac involvement and unstable hemodynamics and in people with acute iron poisoning [143]. There are three iron chelators in widespread clinical use: deferoxamine, deferasirox, and deferiprone (Table 2) [143].

Deferoxamine is a siderophore obtained from Streptomyces pilosus which has been in clinical use since the 1970s [141, 144]. It is hydrophilic and large, with subsequent poor oral bioavailability, and poor blood-brain barrier permeability [144]. It also has a short half-life. Deferoxamine appears to act on extracellular iron [145]. It inhibits the iron redox cycle and modulates gene expression of hypoxia-inducing factor, iron regulatory protein-1, and APP, potentially blocking production of reactive oxygen species [146]. Deferoxamine binds in a 1:1 ratio with iron and is subsequently excreted in the urine and feces [147].

In APP/PS1 double transgenic mice, intranasal deferoxamine inhibited APP processing, induced activation of M2 microglia with amyloid- $\beta$ phagocytic activity while inhibiting M1 proinflammatory microglia, and improved cognitive function [146, 148]. Deferoxamine also reduced amyloid [149] and tau [150] pathology in animal AD models.

In 1991, a placebo-controlled phase II clinical trial reported that $125 \mathrm{mg}$ intramuscular deferoxamine dosed twice daily five times a week slowed cognitive decline in subjects with $\mathrm{AD}$ by $50 \%$ over a 24 -month period [151]. This remains one of the few clinical trials for a potentially disease-modifying

Table 2 Iron chelators in current clinical use

\begin{tabular}{lll}
\hline Agent & Oral bioavailability & Blood-brain barrier passage \\
\hline Deferoxamine & No & Poor \\
Deferasirox & Yes & Limited \\
Deferiprone & Yes & Good \\
\hline
\end{tabular}

drug in $\mathrm{AD}$ that his shown cognitive benefit. At the time, the results were attributed to binding of brain aluminum [151]. The evidence for environmental exposure to aluminum playing a role in $\mathrm{AD}$ subsequently weakened [152], and the trial was never followed up to our knowledge. Deferoxamine's affinity for $\mathrm{Fe}^{3+}$, however, is six times greater than for $\mathrm{Al}^{3+}$, and iron is 1000 -fold more abundant in the brain than aluminum, which suggests the positive results were due to iron chelation, rather than an effect on aluminum.

Deferasirox is an orally bioavailable high-affinity iron chelator which is capable of intracellular iron chelation. In rats, deferasirox prevented age-related accumulation of iron, reduced ferritin and transferrin receptor expression, and reversed altered amyloid- $\beta$ metabolism [153]. Blood-brain barrier passage is limited, but improves when conjugated with lactoferrin [154]. Deferasirox binds at a 2:1 ratio to iron and is excreted in the feces [147]. Lactoferrin-deferasirox conjugates attenuated learning deficits induced by amyloid injection in a rat model of $\mathrm{AD}$ [154].

Deferiprone is an orally bioavailable siderophore with moderate iron-binding affinity [142, 144], which has been in clinical use since the 1980s [141]. It readily crosses the bloodbrain barrier and chelates intracellular iron [145]. It is less aggressive than deferoxamine, which readily depletes the body of iron. Deferiprone penetrates cellular membranes, forms a complex with iron, exits cells, and can redistribute iron to transferrin for reuse $[155,156]$. It binds iron with a $3: 1$ chelator/iron ratio and is primarily excreted via the kidneys [147].

Deferiprone is neuroprotective in neuronal culture models of amyloid- $\beta$ toxicity $[157,158]$, protecting against hydrogen peroxide and $A \beta 1-40$-induced neuronal death [158]. It attenuates amyloid burden and tau phosphorylation in a rabbit model of AD [159].

Clinical trials of deferiprone have taken place in a number of neurodegenerative disorders. A pilot study in Friedreich's ataxia, followed by a 6-month randomized controlled trial, showed that deferiprone can safely reverse pathological brain iron accumulation $[155,160]$. A 12-month trial in neurodegeneration with brain accumulation followed, demonstrating that deferiprone was well tolerated over longer time frames [161]. FAIR-PARK 1, a phase II trial in Parkinson's disease, also showed that deferiprone was well-tolerated and did not lead to iron depletion [67]. Motor symptoms improved and R2* MRI showed a reduction in iron deposition in the substantia nigra [67]. FAIR-PARK 2, a phase III trial of deferiprone in Parkinson's disease, is nearing completion, with results expected in mid-2020.

A clinical of deferiprone in Alzheimer's disease is currently underway, the Deferiprone to Delay Dementia (3D Study; ClincalTrials.gov Identifier NCT03234686). This is a phase II randomized controlled study investigating the safety and efficacy of deferiprone in subjects with prodromal and mild 
AD. The primary outcome is performance on a neuropsychological test battery. Secondary outcomes include brain iron levels as measured by MRI (T2*, QSM).

Clioquinol is an 8 -hydroxyquinoline analogue. It is a copper/zinc ionophore and a moderate iron chelator [162]. It was withdrawn from clinical use due to a purported association with subacute myelo-optico-neuropathy, though whether an association exists is not clear [163]. Complications with large-scale manufacturing prevented further developments [162]. Clioquinol dissociates metals from binding sites in $A \beta$, decreases iron-associated $A \beta 42$ aggregation [164], and stimulates amyloid degradation pathways via metaldependent signalling. In a placebo-controlled phase II trial of 32 patients, clioquinol prevented cognitive deterioration and lowered plasma $A \beta-42$ levels [165].

\section{Iron Chelators Under Development with Potential in Alzheimer's Disease}

A number of compounds with iron-chelating activity have shown potential in in vivo AD models. There are also numerous novel compounds which have recently been developed (Table 3), some of which are described below.

Monoamine oxidase B leads to an increase in hydrogen peroxide and free radicals. A series of compounds combining MAO inhibition with iron chelation activity have been developed [166-168]. One of these, M30, is an orally bioavailable iron chelator which crosses the blood-brain barrier has shown promise in cell line and animal models. It combines monoamine oxidase A and B inhibitory activities with the antioxidant chelator moiety of VK28, an 8-hydroxyquinoline derivative [169]. M30 reduced APP expression and A $\beta$ generation in vitro and reduced amyloid- $\beta$ plaques in aged mice [169]. In APP/PS1 mice, it attenuated cognitive impairments, reduced cerebral iron accumulation, decreased cerebral APP levels, and reduced amyloid- $\beta$ and tau levels [170]. This drug has not yet been tested in humans with $A D$ to our knowledge.

There are several other iron chelators with in vitro evidence in support of a potential benefit in AD. A novel class of 2amido-3-hydroxypyridin-4-one iron chelators shows neuroprotective properties in cell cultures against $\beta$-amyloidinduced toxicity [171]. Hydroxylated chalcones have recently been designed as dual-function inhibitors, with action against amyloid- $\beta$ peptide aggregation and ferroptosis [172]. These have been shown in cell lines to provide protection against A $\beta 1-42$ aggregation-induced toxicity and against ferroptosis [172]. HLA20A is a selective acetylcholinesterase inhibitor with site-activated chelating activity. It is activated following inhibition of acetylcholinesterase to liberate an active chelator, HLA20, which has neuroprotective activities. It has been shown to lower APP expression and amyloid- $\beta$ generation and to reduce iron-induced aggregation [173].

A number of other dual-function therapeutics have been developed with iron-chelating and acetylcholinesteraseinhibiting properties. Tacrine-(hydroxybenzoyl-pyridone) hybrids, combining acetylcholineserase inhibition and iron-chelating capacity have been developed [174]. There are also tacrine-deferiprone hybrids [175]. Novel dihydropyrimidinone-derived selenoesters have been synthesized with anti-oxidant activity via lipid peroxidation inhibition and iron chelation activity as well as acetylcholinesterase inhibition [176]. Quinazoline and pyrido(3,2-d)pyrimidine, and 3-hydroxy-4-pyridinone)-benzorufan-based compounds have also been synthesized, with dual cholinesterase
Table 3 Some iron chelators and related compounds under development with potential in $\mathrm{AD}$

\begin{tabular}{ll}
\hline Agent & Mechanism of action \\
\hline M30 & MAO-I + IC \\
2-Amido-3-hydroxypyridin-4-one compounds & IC \\
Hydroxylated chalcones & Anti-A $\beta$ aggregation + anti-ferroptotic \\
HLA20A & ACh-I + IC \\
Tacrine-(hydroxybenzoyl-pyridone) hybrids & ACh-I + IC \\
Tacrine-deferiprone & ACh-I + IC \\
Dihydropyrimidinone-derived selenoesters & ACh-I + IC + anti-oxidant \\
Quinazoline-pyrido-benzorufan-based compounds & ACh-I + IC \\
3,4-HP-based compounds & Anti-A $\beta$ aggregation + ACh-I + IC \\
Benzothiazone-based compounds & Anti-A $\beta$ aggregation + ACh-I + IC \\
Coumarin-quinoline hybrids & ACh-I + IC \\
1-Phenyl-3-hydroxyl-4-pyridinone derivatives & Anti-A $\beta$ aggregation + IC + anti-oxidant \\
Cu (atsm) & Anti-ferroptotic \\
PBPT & ACh-I + CI \\
\hline
\end{tabular}

MAO-I = monoamine oxidase inhibitor; $\mathrm{IC}=$ iron chelator; $\mathrm{ACh}-\mathrm{I}=$ acetylcholinesterase inhibitor 
inhibition and iron-chelating properties [177, 178]. Similarly, multifunctional iron chelators with anti-A $\beta$-aggregating and acetylcholinesterase-inhibiting activity have been developed from 3-hydroxyl-4-pyridinone (3,4-HP) and benzothiazole molecular moieties [179].

Circumin has been proposed as an AD therapeutic in light of its iron-binding capability [180]. A number of derivatives have been developed, including coumarin-quinoline hybrids with acetylcholinesterase and iron chelation activity [181] and hybrids of hydroxypyridinone and coumarin, which ameliorated cognitive dysfunction in scopolamine-induced $\mathrm{AD}$ mice [182].

Novel 1-phenyl-3-hydroxyl-4-pyridinone derivatives with iron-binding capabilities have been synthesized as potential AD therapeutics by incorporating the 3-hydroxy-4pyridinone moiety from deferiprone into the scaffold of $\mathrm{H3}$ receptor antagonists. Some of these combine iron chelating, amyloid- $\beta$ aggregation inhibition, metal chelating, and free radical scavenging actions [183].

Chelators based on Schiff bases, particularly hydrazones and thiosemicarbazones, also have potential in neurodegenerative diseases based on their ability to suppress oxidative stress caused by redox-active metals and metal-induced aggregation of amyloid beta [139]. Cholyl hydrazones have been shown to can reduce amyloid- $\beta$ toxicity and oxidative stress in cell lines [139]. Diacetyl-bis(4-methyl-3thiosemicarbazonato)copper ${ }^{\mathrm{II}}\left(\mathrm{Cu}^{\mathrm{II}}(\mathrm{atsm})\right)$ is a bisthiosemicarbazone that protects against lipid peroxidation and ferroptotic lethality in vitro [184]. $\mathrm{Cu}^{\mathrm{II}}($ atsm) is orally bioavailable and crosses the blood-brain barrier [184]. Phase I trials in Parkinson's and motor neuron diseases have recently been completed with promising results $[185,186]$. Cu ${ }^{\mathrm{II}} \mathrm{GTSM}$ lowered A $\beta$ levels and phosphorylated tau levels in cell culture and APP/PS1 transgenic mice [187].

Multifunctional hybrids based on hydrazones and thiosemicarbazones are in development. This includes novel adamantine-based semicarbazones and hydrazones [188] and hybrid molecules containing a metal binding unit, a thiosemicarbazone, and acetylcholinesterase inhibitor such as PBPT (pyridoxal 4-N-(1-benzylpiperidin-4yl)thiosemicarbazone) [189].

Very few iron chelators have made it to clinical trials in humans in spite of the development of the above and other compounds. A search of clinicaltrials.gov using the terms "iron" and "Alzheimer's" on 24 June 2020 only yielded the 3D study discussed above.

\section{Conclusion}

An extensive body of data in support of a role of iron in the pathophysiology of Alzheimer's disease is emerging. This work ties in with the pathology of amyloid- $\beta$ and tau at many levels. Cell line and animal studies of iron chelators for $\mathrm{AD}$ show encouraging results. In spite of this, there has been very little work on iron-lowering strategies in humans with $\mathrm{AD}$, likely due to an overemphasis on amyloid-lowering strategies which have been overwhelmingly disappointing to date. Given the growing number of iron-chelating compounds with potential disease-modifying efficacy, and the availability of MRI and CSF biomarkers of iron load, there is considerable scope to explore this therapeutic class in $\mathrm{AD}$.

Acknowledgments: Dr. Gleason is supported by scholarships from the Dementia Centre for Research Collaboration and the Yuligbar Foundation.

Required Author Forms Disclosure forms provided by the authors are available with the online version of this article.

\section{References}

1. World Health Organization. Global, regional, and national burden of Alzheimer's disease and other dementias, 1990-2016: a systematic analysis for the Global Burden of Disease Study 2016. Lancet Neurol 2019;18:88-106.

2. DeTure MA, Dickson DW. The neuropathological diagnosis of Alzheimer's disease. Mol Neurodegener 2019;14:32.

3. Hardy JA, Higgins GA. Alzheimer's disease: the amyloid cascade hypothesis. Science (New York, NY). 1992;256:184-5.

4. Long JM, Holtzman DM. Alzheimer disease: an update on pathobiology and treatment strategies. Cell. 2019;179:312-39.

5. Schneider L. A resurrection of aducanumab for Alzheimer's disease. Lancet Neurol 2020;19:111-2.

6. Gleason A, Ayton S, Bush AI. Unblinded by the light: amyloidrelated imaging abnormalities in Alzheimer's clinical trials. Eur J Neurol. 2020Aug 17. https://doi.org/10.1111/ene.14484. Epub ahead of print

7. Sperling RA, Rentz DM, Johnson KA, Karlawish J, Donohue M, Salmon DP, et al. The A4 study: stopping AD before symptoms begin? Sci Transl Med. 2014;6:228fs13-fs13.

8. Mills SM, Mallmann J, Santacruz AM, Fuqua A, Carril M, Aisen PS, et al. Preclinical trials in autosomal dominant AD: implementation of the DIAN-TU trial. Rev Neurol (Paris) 2013;169:737-43.

9. Driscoll I, Troncoso J. Asymptomatic Alzheimer's disease: a prodrome or a state of resilience? Curr Alzheimer Res 2011;8:330-5.

10. Dixon SJ, Lemberg KM, Lamprecht MR, Skouta R, Zaitsev EM, Gleason CE, et al. Ferroptosis: an iron-dependent form of nonapoptotic cell death. Cell. 2012;149:1060-72.

11. Stockwell BR, Friedmann Angeli JP, Bayir H, Bush AI, Conrad M, Dixon SJ, et al. Ferroptosis: a regulated cell death nexus linking metabolism, redox biology, and disease. Cell. 2017;171: 273-85.

12. Derry PJ, Hegde ML, Jackson GR, Kayed R, Tour JM, Tsai AL, et al. Revisiting the intersection of amyloid, pathologically modified tau and iron in Alzheimer's disease from a ferroptosis perspective. Prog Neurobiol 2020;184:101716.

13. Zoroddu MA, Aaseth J, Crisponi G, Medici S, Peana M, Nurchi VM. The essential metals for humans: a brief overview. J Inorg Biochem 2019;195:120-9. 
14. Mezzaroba L, Alfieri DF, Colado Simao AN, Vissoci Reiche EM. The role of zinc, copper, manganese and iron in neurodegenerative diseases. Neurotoxicology. 2019;74:230-41.

15. Connor JR, Menzies SL, Burdo JR, Boyer PJ. Iron and iron management proteins in neurobiology. Pediatr Neurol 2001;25:11829.

16. Rouault TA. Systemic iron metabolism: a review and implications for brain iron metabolism. Pediatr Neurol 2001;25:130-7.

17. Kell DB. Iron behaving badly: inappropriate iron chelation as a major contributor to the aetiology of vascular and other progressive inflammatory and degenerative diseases. BMC Med Genet 2009;2:2.

18. Connor JR, Menzies SL. Relationship of iron to oligodendrocytes and myelination. Glia. 1996;17:83-93.

19. Chen P, Miah MR, Aschner M. Metals and Neurodegeneration. F1000Res. 2016 Mar 17;5:F1000 Faculty Rev-366. https:/doi. org/10.12688/f1000research.7431.1

20. Salvador G. Iron in neuronal function and dysfunction. BioFactors (Oxford, England). 2010;36:103-10.

21. Sipe J, Lee P, Beutler E. Brain iron metabolism and neurodegenerative disorders. Dev Neurosci 2002;24:188-96.

22. Urrutia PJ, Mena NP, Nunez MT. The interplay between iron accumulation, mitochondrial dysfunction, and inflammation during the execution step of neurodegenerative disorders. Front Pharmacol 2014;5:38.

23. Huat TJ, Camats-Perna J, Newcombe EA, Valmas N, Kitazawa M, Medeiros R. Metal toxicity links to Alzheimer's disease and neuroinflammation. J Mol Biol 2019;431:1843-68.

24. Fenton HJH. LXXIII. - oxidation of tartaric acid in presence of iron. J Chem Soc Trans 1894;65:899-910.

25. Schneider C, Porter NA, Brash AR. Routes to 4-hydroxynonenal: fundamental issues in the mechanisms of lipid peroxidation. J Biol Chem 2008;283:15539-43.

26. Sayre LM, Lin D, Yuan Q, Zhu X, Tang X. Protein adducts generated from products of lipid oxidation: focus on HNE and one. Drug Metab Rev 2006;38:651-75.

27. Dalle-Donne I, Aldini G, Carini M, Colombo R, Rossi R, Milzani A. Protein carbonylation, cellular dysfunction, and disease progression. J Cell Mol Med 2006;10:389-406.

28. Grimsrud PA, Xie H, Griffin TJ, Bernlohr DA. Oxidative stress and covalent modification of protein with bioactive aldehydes. $\mathrm{J}$ Biol Chem 2008;283:21837-41.

29. Ratan RR. Does iron loading of oxygen-sensing prolyl hydroxylases rather than random Fenton-driven radical formation drive programmed ferroptosis and degeneration in neurological diseases? Curr Opin Physiol 2019;7:60-5.

30. Cheignon C, Tomas M, Bonnefont-Rousselot D, Faller P, Hureau C, Collin F. Oxidative stress and the amyloid beta peptide in Alzheimer's disease. Redox Biol 2018;14:450-64.

31. Acevedo K, Masaldan S, Opazo CM, Bush AI. Redox active metals in neurodegenerative diseases. J Biol Inorg Chem 2019;24:1141-57.

32. Mills E, Dong XP, Wang F, Xu H. Mechanisms of brain iron transport: insight into neurodegeneration and CNS disorders. Future Med Chem 2010;2:51-64.

33. Liu JL, Fan YG, Yang ZS, Wang ZY, Guo C. Iron and Alzheimer's disease: from pathogenesis to therapeutic implications. Front Neurosci 2018; 12:632.

34. Sayre LM, Perry G, Harris PL, Liu Y, Schubert KA, Smith MA. In situ oxidative catalysis by neurofibrillary tangles and senile plaques in Alzheimer's disease: a central role for bound transition metals. J Neurochem 2000;74:270-9.

35. Goodman L. Alzheimer's disease; a clinico-pathologic analysis of twenty-three cases with a theory on pathogenesis. J Nerv Ment Dis 1953;118:97-130.
36. Duce JA, Tsatsanis A, Cater MA, James SA, Robb E, Wikhe K, et al. Iron-export ferroxidase activity of beta-amyloid precursor protein is inhibited by zinc in Alzheimer's disease. Cell. 2010;142:857-67.

37. Ayton S, Lei P, Hare DJ, Duce JA, George JL, Adlard PA, et al. Parkinson's disease iron deposition caused by nitric oxide-induced loss of APP. J Neurosci. 2015;35:3591-7.

38. Connor JR, Snyder BS, Beard JL, Fine RE, Mufson EJ. Regional distribution of iron and iron-regulatory proteins in the brain in aging and Alzheimer's disease. J Neurosci Res 1992;31:327-35.

39. Good PF, Perl DP, Bierer LM, Schmeidler J. Selective accumulation of aluminum and iron in the neurofibrillary tangles of Alzheimer's disease: a laser microprobe (LAMMA) study. AnnNeurol. 1992;31:286-92.

40. Smith MA, Harris PLR, Sayre LM, Perry G. Iron accumulation in Alzheimer's disease is a source of redox-generated free radicals. PNAS. 1997;94:9866-8.

41. Jellinger K, Paulus W, Grundke-Iqbal I, Riederer P, Youdim MB. Brain iron and ferritin in Parkinson's and Alzheimer's diseases. J Neural Transm Park Dis Dement Sect 1990;2:327-40.

42. Smith MA, Harris PL, Sayre LM, Perry G. Iron accumulation in Alzheimer disease is a source of redox-generated free radicals. Proc Natl Acad Sci U S A 1997;94:9866-8.

43. Bartzokis G, Sultzer D, Cummings J, Holt LE, Hance DB, Henderson VW, et al. In vivo evaluation of brain iron in Alzheimer disease using magnetic resonance imaging. Arch Gen Psychiatry 2000;57:47-53.

44. Luo Z, Zhuang X, Kumar D, Wu X, Yue C, Han C, et al. The correlation of hippocampal T2-mapping with neuropsychology test in patients with Alzheimer's disease. PLoS One 2013;8: e76203.

45. Moon Y, Han SH, Moon WJ. Patterns of brain iron accumulation in vascular dementia and Alzheimer's dementia using quantitative susceptibility mapping imaging. J Alzheimers Dis 2016;51:73745.

46. Raven EP, Lu PH, Tishler TA, Heydari P, Bartzokis G. Increased iron levels and decreased tissue integrity in hippocampus of Alzheimer's disease detected in vivo with magnetic resonance imaging. J Alzheimers Dis 2013;37:127-36.

47. van Rooden S, Doan NT, Versluis MJ, Goos JD, Webb AG, Oleksik AM, et al. 7T T(2)*-weighted magnetic resonance imaging reveals cortical phase differences between early- and lateonset Alzheimer's disease. Neurobiol Aging 2015;36:20-6.

48. Connor JR, Menzies SL, St Martin SM, Mufson EJ. A histochemical study of iron, transferrin, and ferritin in Alzheimer's diseased brains. J Neurosci Res 1992;31:75-83.

49. Collingwood JF, Mikhaylova A, Davidson M, Batich C, Streit WJ, Terry J, et al. In situ characterization and mapping of iron compounds in Alzheimer's disease tissue. J Alzheimers Dis 2005;7:267-72.

50. Baltes C, Princz-Kranz F, Rudin M, Mueggler T.Detecting amyloid-beta plaques in Alzheimer's disease. Methods Mol Biol. 2011;711:511-33.

51. Meadowcroft MD, Connor JR, Smith MB, Yang QX. MRI and histological analysis of beta-amyloid plaques in both human Alzheimer's disease and APP/PS1 transgenic mice. J Magn Reson Imaging 2009;29:997-1007.

52. Collingwood JF, Chong RK, Kasama T, Cervera-Gontard L, Dunin-Borkowski RE, Perry G, et al. Three-dimensional tomographic imaging and characterization of iron compounds within Alzheimer's plaque core material. J Alzheimers Dis 2008;14:23545.

53. Andrasi E, Farkas E, Scheibler H, Reffy A, Bezur L. Al, Zn, Cu, $\mathrm{Mn}$ and Fe levels in brain in Alzheimer's disease. Arch Gerontol Geriatr 1995;21:89-97. 
54. Ghadery C, Pirpamer L, Hofer E, Langkammer C, Petrovic K, Loitfelder M, et al. R2* mapping for brain iron: associations with cognition in normal aging. Neurobiol Aging 2015;36:925-32.

55. Acosta-Cabronero J, Betts MJ, Cardenas-Blanco A, Yang S, Nestor PJ. In vivo MRI mapping of brain iron deposition across the adult lifespan. J Neurosci 2016;36:364-74.

56. Ayton S, Faux NG, Bush AI. Ferritin levels in the cerebrospinal fluid predict Alzheimer's disease outcomes and are regulated by APOE. Nat Commun 2015;6:6760.

57. Smith MA, Zhu X, Tabaton M, Liu G, McKeel DW, Jr., Cohen $\mathrm{ML}$, et al. Increased iron and free radical generation in preclinical Alzheimer disease and mild cognitive impairment. J Alzheimers Dis 2010;19:363-72.

58. Ward RJ, Dexter DT, Crichton RR. Neurodegenerative diseases and therapeutic strategies using iron chelators. J Trace Elem Med Biol 2015;31:267-73.

59. Belaidi AA, Bush AI. Iron neurochemistry in Alzheimer's disease and Parkinson's disease: targets for therapeutics. J Neurochem 2016;139 Suppl 1:179-97.

60. Hocq A, Brouette N, Saussez S, Luhmer M, Gillis P, Gossuin Y. Variable-field relaxometry of iron-containing human tissues: a preliminary study. Contrast Media Mol Imaging 2009;4:157-64.

61. Bulk M, Kenkhuis B, van der Graaf LM, Goeman JJ, Natte R, van der Weerd L. Postmortem T2*-weighted MRI imaging of cortical iron reflects severity of Alzheimer's disease. J Alzheimers Dis 2018;65:1125-37.

62. Du L, Zhao Z, Cui A, Zhu Y, Zhang L, Liu J, et al. Increased iron deposition on brain quantitative susceptibility mapping correlates with decreased cognitive function in Alzheimer's disease. ACS Chem Neurosci 2018;9:1849-57.

63. Gao L, Jiang Z, Cai Z, Cai M, Zhang Q, Ma Y, et al. Brain iron deposition analysis using susceptibility weighted imaging and its association with body iron level in patients with mild cognitive impairment. Mol Med Rep 2017;16:8209-15.

64. Ayton S, Fazlollahi A, Bourgeat P, Raniga P, Ng A, Lim YY, et al. Cerebral quantitative susceptibility mapping predicts amyloidbeta-related cognitive decline. Brain. 2017;140:2112-9.

65. Yates PA, Sirisriro R, Villemagne VL, Farquharson S, Masters $\mathrm{CL}$, Rowe CC, et al. Cerebral microhemorrhage and brain betaamyloid in aging and Alzheimer disease. Neurology. 2011;77:4854.

66. Ayton S, Faux NG, Bush AI, Alzheimer's disease neuroimaging I. Ferritin levels in the cerebrospinal fluid predict Alzheimer's disease outcomes and are regulated by APOE. Nat Commun 2015;6: 6760.

67. Devos D, Moreau C, Devedjian JC, Kluza J, Petrault M, Laloux C, et al. Targeting chelatable iron as a therapeutic modality in Parkinson's disease. Antioxid Redox Signal 2014;21:195-210.

68. Earley CJ, Connor JR, Beard JL, Malecki EA, Epstein DK, Allen RP. Abnormalities in CSF concentrations of ferritin and transferrin in restless legs syndrome. Neurology. 2000;54:1698-700.

69. Palmqvist S, Zetterberg H, Mattsson N, Johansson P, Minthon L, Blennow K, et al. Detailed comparison of amyloid PET and CSF biomarkers for identifying early Alzheimer disease. Neurology. 2015;85:1240-9.

70. Diouf I, Fazlollahi A, Bush AI, Ayton S. Cerebrospinal fluid ferritin levels predict brain hypometabolism in people with underlying beta-amyloid pathology. Neurobiol Dis 2019;124:335-9.

71. Ayton S, Diouf I, Bush AI. Evidence that iron accelerates Alzheimer's pathology: a CSF biomarker study. J Neurol Neurosurg Psychiatry 2018;89:456-60.

72. Goozee K, Chatterjee P, James I, Shen K, Sohrabi HR, Asih PR, et al. Elevated plasma ferritin in elderly individuals with high neocortical amyloid-beta load. Mol Psychiatry 2018;23:1807-12.

73. Palmqvist S, Zetterberg H, Mattsson N, Johansson P, Alzheimer's Disease Neuroimaging I, Minthon L, et al. Detailed comparison of amyloid PET and CSF biomarkers for identifying early Alzheimer disease. Neurology. 2015;85:1240-9.

74. Ashraf A, Alepuz Guillen JA, Aljuhani M, Hubens C, So PW. Low cerebrospinal fluid levels of melanotransferrin are associated with conversion of mild cognitively impaired subjects to Alzheimer's disease. Front Neurosci 2019;13:181.

75. Kweon OJ, Youn YC, Lim YK, Lee MK, Kim HR. Clinical utility of serum hepcidin and iron profile measurements in Alzheimer's disease. J Neurol Sci 2019;403:85-91.

76. Raha AA, Vaishnav RA, Friedland RP, Bomford A, RahaChowdhury R. The systemic iron-regulatory proteins hepcidin and ferroportin are reduced in the brain in Alzheimer's disease. Acta Neuropathol Commun 2013;1:55.

77. Nemeth E, Tuttle MS, Powelson J, Vaughn MB, Donovan A, Ward DM, et al. Hepcidin regulates cellular iron efflux by binding to ferroportin and inducing its internalization. Science (New York, NY). 2004;306:2090-3.

78. Dusek P, Schneider SA, Aaseth J. Iron chelation in the treatment of neurodegenerative diseases. J Trace Elem Med Biol 2016;38: 81-92.

79. Tanzi RE, Gusella JF, Watkins PC, Bruns GA, St George-Hyslop P, Van Keuren ML, et al. Amyloid beta protein gene: cDNA, mRNA distribution, and genetic linkage near the Alzheimer locus. Science (New York, NY). 1987;235:880-4.

80. O'Brien RJ, Wong PC. Amyloid precursor protein processing and Alzheimer's disease. Annu Rev Neurosci 2011;34:185-204.

81. Belaidi AA, Gunn AP, Wong BX, Ayton S, Appukuttan AT, Roberts BR, et al. Marked age-related changes in brain iron homeostasis in amyloid protein precursor knockout mice. Neurotherapeutics 2018;15:1055-62.

82. Rogers JT, Randall JD, Cahill CM, Eder PS, Huang X, Gunshin $\mathrm{H}$, et al. An iron-responsive element type II in the 5 -untranslated region of the Alzheimer's amyloid precursor protein transcript. J Biol Chem 2002;277:45518-28.

83. Cho HH, Cahill CM, Vanderburg CR, Scherzer CR, Wang B, Huang X, et al. Selective translational control of the Alzheimer amyloid precursor protein transcript by iron regulatory protein- $1 . \mathrm{J}$ Biol Chem 2010;285:31217-32.

84. Li X, Liu Y, Zheng Q, Yao G, Cheng P, Bu G, et al. Ferritin light chain interacts with PEN-2 and affects gamma-secretase activity. Neurosci Lett 2013;548:90-4.

85. Lumsden AL, Rogers JT, Majd S, Newman M, Sutherland GT, Verdile G, Lardelli M. Dysregulation of Neuronal Iron Homeostasis as an Alternative Unifying Effect of Mutations Causing Familial Alzheimer's Disease. Front Neurosci. 2018 Aug 13;12:533. https://doi.org/10.3389/fnins.2018.00533

86. Bousejra-ElGarah F, Bijani C, Coppel Y, Faller P, Hureau C. Iron(II) binding to amyloid-beta, the Alzheimer's peptide. Inorg Chem 2011;50:9024-30

87. Jiang D, Li X, Williams R, Patel S, Men L, Wang Y, et al. Ternary complexes of iron, amyloid-beta, and nitrilotriacetic acid: binding affinities, redox properties, and relevance to iron-induced oxidative stress in Alzheimer's disease. Biochemistry. 2009;48:793947.

88. Telling ND, Everett J, Collingwood JF, Dobson J, van der Laan G, Gallagher JJ, et al. Iron biochemistry is correlated with amyloid plaque morphology in an established mouse model of Alzheimer's disease. Cell Chem Biol. 2017;24:1205-15.e3.

89. van Bergen JMG, Li X, Quevenco FC, Gietl AF, Treyer V, Meyer $\mathrm{R}$, et al. Simultaneous quantitative susceptibility mapping and flutemetamol-PET suggests local correlation of iron and betaamyloid as an indicator of cognitive performance at high age. Neuroimage. 2018;174:308-16.

90. Rao SS, Adlard PA. Untangling Tau and Iron: Exploring the Interaction Between Iron and Tau in Neurodegeneration. Front 
Mol Neurosci. 2018 Aug 17;11:276. https://doi.org/10.3389/ fnmol.2018.00276

91. Hansra GK, Popov G, Banaczek PO, Vogiatzis M, Jegathees T, Goldbury CS, et al. The neuritic plaque in Alzheimer's disease: perivascular degeneration of neuronal processes. Neurobiol Aging 2019;82:88-101.

92. Lovell MA, Xiong S, Xie C, Davies P, Markesbery WR. Induction of hyperphosphorylated tau in primary rat cortical neuron cultures mediated by oxidative stress and glycogen synthase kinase- 3 . J Alzheimers Dis 2004;6:659-71; discussion 73-81.

93. Garcia de Ancos J, Correas I, Avila J. Differences in microtubule binding and self-association abilities of bovine brain tau isoforms. J Biol Chem. 1993;268:7976-82.

94. Ledesma MD, Avila J, Correas I. Isolation of a phosphorylated soluble tau fraction from Alzheimer's disease brain. Neurobiol Aging 1995; 16:515-22.

95. Yamamoto A, Shin RW, Hasegawa K, Naiki H, Sato H, Yoshimasu F, et al. Iron (III) induces aggregation of hyperphosphorylated tau and its reduction to iron (II) reverses the aggregation: implications in the formation of neurofibrillary tangles of Alzheimer's disease. J Neurochem 2002;82:1137-47.

96. Mantyh PW, Ghilardi JR, Rogers S, DeMaster E, Allen CJ, Stimson ER, et al. Aluminum, iron, and zinc ions promote aggregation of physiological concentrations of beta-amyloid peptide. $\mathrm{J}$ Neurochem 1993;61:1171-4.

97. Huang X, Atwood CS, Moir RD, Hartshorn MA, Tanzi RE, Bush AI. Trace metal contamination initiates the apparent auto-aggregation, amyloidosis, and oligomerization of Alzheimer's Abeta peptides. J Biol Inorg Chem 2004;9:954-60.

98. Huang X, Atwood CS, Hartshorn MA, Multhaup G, Goldstein LE, Scarpa RC, et al. The A beta peptide of Alzheimer's disease directly produces hydrogen peroxide through metal ion reduction. Biochemistry. 1999;38:7609-16.

99. Schubert $\mathrm{D}$, Chevion $\mathrm{M}$. The role of iron in beta amyloid toxicity. Biochem Biophys Res Commun 1995;216:702-7.

100. Liu B, Moloney A, Meehan S, Morris K, Thomas SE, Serpell LC, et al. Iron promotes the toxicity of amyloid beta peptide by impeding its ordered aggregation. J Biol Chem 2011;286:4248-56.

101. Rottkamp CA, Raina AK, Zhu X, Gaier E, Bush AI, Atwood CS, et al. Redox-active iron mediates amyloid-beta toxicity. Free Radic Biol Med 2001;30:447-50.

102. Boopathi S, Kolandaivel P. Fe(2+) binding on amyloid betapeptide promotes aggregation. Proteins. 2016;84:1257-74.

103. Rival T, Page RM, Chandraratna DS, Sendall TJ, Ryder E, Liu B, et al. Fenton chemistry and oxidative stress mediate the toxicity of the beta-amyloid peptide in a Drosophila model of Alzheimer's disease. Eur J Neurosci 2009;29:1335-47.

104. Kuperstein F, Yavin E. Pro-apoptotic signaling in neuronal cells following iron and amyloid beta peptide neurotoxicity. J Neurochem 2003;86:114-25.

105. Lovell MA, Soman S, Bradley MA. Oxidatively modified nucleic acids in preclinical Alzheimer's disease (PCAD) brain. Mech Ageing Dev 2011;132:443-8.

106. Dalle-Donne I, Giustarini D, Colombo R, Rossi R, Milzani A. Protein carbonylation in human diseases. Trends Mol Med 2003;9:169-76.

107. Balejcikova L, Siposova K, Kopcansky P, Safarik I. Fe(II) formation after interaction of the amyloid beta-peptide with iron-storage protein ferritin. J Biol Phys 2018;44:237-43.

108. Butterfield DA, Lauderback CM. Lipid peroxidation and protein oxidation in Alzheimer's disease brain: potential causes and consequences involving amyloid beta-peptide-associated free radical oxidative stress. Free Radic Biol Med 2002;32:1050-60.

109. Angelova DM, Brown DR. Microglia and the aging brain: are senescent microglia the key to neurodegeneration? J Neurochem 2019;151:676-88.
110. McIntosh A, Mela V, Harty C, Minogue AM, Costello DA, Kerskens $\mathrm{C}$, et al. Iron accumulation in microglia triggers a cascade of events that leads to altered metabolism and compromised function in APP/PS1 mice. Brain Pathol 2019;29:606-21.

111. Yang Wan S, SriRamaratnam R, Welsch Matthew E, Shimada K, Skouta R, Viswanathan Vasanthi S, et al. Regulation of ferroptotic cancer cell death by GPX4. Cell. 2014;156:317-31.

112. Ursini F, Maiorino M, Valente M, Ferri L, Gregolin C. Purification from pig liver of a protein which protects liposomes and biomembranes from peroxidative degradation and exhibits glutathione peroxidase activity on phosphatidylcholine hydroperoxides. Biochim Biophys Acta, Lipids Lipid Metab 1982;710: 197-211.

113. Friedmann Angeli JP, Schneider M, Proneth B, Tyurina YY, Tyurin VA, Hammond VJ, et al. Inactivation of the ferroptosis regulator Gpx4 triggers acute renal failure in mice. Nat Cell Biol 2014;16:1180-91.

114. Mou Y, Wang J, Wu J, He D, Zhang C, Duan C, et al. Ferroptosis, a new form of cell death: opportunities and challenges in cancer. J Hematol Oncol 2019;12:34.

115. Miyake S, Murai S, Kakuta S, Uchiyama Y, Nakano H. Identification of the hallmarks of necroptosis and ferroptosis by transmission electron microscopy. Biochem Biophys Res Commun 2020;527:839-44.

116. Tang M, Chen Z, Wu D, Chen L. Ferritinophagy/ferroptosis: ironrelated newcomers in human diseases. J Cell Physiol 2018;233: 9179-90.

117. Moroishi T, Yamauchi T, Nishiyama M, Nakayama KI. HERC2 targets the iron regulator FBXL5 for degradation and modulates iron metabolism. J Biol Chem 2014;289:16430-41.

118. Abdalkader M, Lampinen R, Kanninen KM, Malm TM, Liddell JR. Targeting Nrf2 to Suppress Ferroptosis and Mitochondrial Dysfunction in Neurodegeneration. Front Neurosci. 2018 Jul 10;12:466. doi: 10.3389/fnins.2018.00466

119. Adibhatla RM, Hatcher JF. Lipid oxidation and peroxidation in CNS health and disease: from molecular mechanisms to therapeutic opportunities. Antioxid Redox Signal 2010;12:125-69.

120. Yan N, Zhang J. Iron Metabolism, Ferroptosis, and the Links With Alzheimer's Disease. Front Neurosci. 2020 Jan 29;13:1443. https://doi.org/10.3389/fnins.2019.01443

121. Hambright WS, Fonseca RS, Chen L, Na R, Ran Q. Ablation of ferroptosis regulator glutathione peroxidase 4 in forebrain neurons promotes cognitive impairment and neurodegeneration. Redox Biol 2017;12:8-17.

122. Lloret A, Esteve D, Monllor P, Cervera-Ferri A, Lloret A. The effectiveness of vitamin E treatment in Alzheimer's disease. Int $\mathrm{J}$ Mol Sci 2019;20:879.

123. Cai P, Fang SQ, Yang HL, Yang XL, Liu QH, Kong LY, et al. Donepezil-butylated hydroxytoluene (BHT) hybrids as antiAlzheimer's disease agents with cholinergic, antioxidant, and neuroprotective properties. Eur J Med Chem 2018;157:161-76.

124. Thal LJ, Grundman M, Berg J, Ernstrom K, Margolin R, Pfeiffer $\mathrm{E}$, et al. Idebenone treatment fails to slow cognitive decline in Alzheimer's disease. Neurology. 2003;61:1498-502.

125. Senin U, Parnetti L, Barbagallo-Sangiorgi G, Bartorelli L, Bocola $\mathrm{V}$, Capurso A, et al. Idebenone in senile dementia of Alzheimer type: a multicentre study. Arch Gerontol Geriatr 1992;15:249-60.

126. Weyer G, Babej-Dölle RM, Hadler D, Hofmann S, Herrmann WM. A controlled study of 2 doses of idebenone in the treatment of Alzheimer's disease. Neuropsychobiology. 1997;36:73-82.

127. Khalaf SS, Hafez MM, Mehanna ET, Mesbah NM, Abo-Elmatty DM. Combined vildagliptin and memantine treatment downregulates expression of amyloid precursor protein, and total and phosphorylated tau in a rat model of combined Alzheimer's disease and type 2 diabetes. Naunyn Schmiedeberg's Arch Pharmacol 2019;392:685-95. 
128. Ma QH, Jiang LF, Mao JL, Xu WX, Huang M. Vildagliptin prevents cognitive deficits and neuronal apoptosis in a rat model of Alzheimer's disease. Mol Med Rep 2018;17:4113-9.

129. Kosaraju J, Murthy V, Khatwal RB, Dubala A, Chinni S, Muthureddy Nataraj SK, et al. Vildagliptin: an anti-diabetes agent ameliorates cognitive deficits and pathology observed in streptozotocin-induced Alzheimer's disease. J Pharm Pharmacol 2013;65:1773-84.

130. Kosaraju J, Holsinger RMD, Guo L, Tam KY. Linagliptin, a dipeptidyl peptidase-4 inhibitor, mitigates cognitive deficits and pathology in the 3xTg-AD mouse model of Alzheimer's disease. Mol Neurobiol 2017;54:6074-84

131. Kornelius E, Lin CL, Chang HH, Li HH, Huang WN, Yang YS, et al. DPP-4 inhibitor linagliptin attenuates $\mathrm{A} \beta$-induced cytotoxicity through activation of AMPK in neuronal cells. CNS Neurosci Ther 2015;21:549-57.

132. Zhang SQ, Obregon D, Ehrhart J, Deng J, Tian J, Hou H, et al. Baicalein reduces $\beta$-amyloid and promotes nonamyloidogenic amyloid precursor protein processing in an Alzheimer's disease transgenic mouse model. J Neurosci Res 2013;91:1239-46.

133. Gu XH, Xu LJ, Liu ZQ, Wei B, Yang YJ, Xu GG, et al. The flavonoid baicalein rescues synaptic plasticity and memory deficits in a mouse model of Alzheimer's disease. Behav Brain Res 2016;311:309-21.

134. Di Meco A, Li JG, Blass BE, Abou-Gharbia M, Lauretti E, Praticò D. 12/15-lipoxygenase inhibition reverses cognitive impairment, brain amyloidosis, and tau pathology by stimulating autophagy in aged triple transgenic mice. Biol Psychiatry 2017;81:92-100.

135. Chu J, Li JG, Giannopoulos PF, Blass BE, Childers W, AbouGharbia M, et al. Pharmacologic blockade of 12/15lipoxygenase ameliorates memory deficits, $\mathrm{A} \beta$ and tau neuropathology in the triple-transgenic mice. Mol Psychiatry 2015;20: 1329-38.

136. Di Meco A, Lauretti E, Vagnozzi AN, Praticò D. Zileuton restores memory impairments and reverses amyloid and tau pathology in aged Alzheimer's disease mice. Neurobiol Aging 2014;35:245864.

137. Chu J, Li JG, Praticò D. Zileuton improves memory deficits, amyloid and tau pathology in a mouse model of Alzheimer's disease with plaques and tangles. PLoS One 2013;8:e70991.

138. Cardoso BR, Roberts BR, Malpas CB, Vivash L, Genc S, Saling MM, et al. Supranutritional sodium selenate supplementation delivers selenium to the central nervous system: results from a randomized controlled pilot trial in Alzheimer's disease. Neurotherapeutics 2019;16:192-202.

139. D'Acunto CW, Kaplanek R, Gbelcova H, Kejik Z, Briza T, Vasina L, et al. Metallomics for Alzheimer's disease treatment: use of new generation of chelators combining metal-cation binding and transport properties. Eur J Med Chem 2018;150:140-55.

140. Hegde ML, Bharathi P, Suram A, Venugopal C, Jagannathan R, Poddar P, et al. Challenges associated with metal chelation therapy in Alzheimer's disease. J Alzheimers Dis 2009;17:457-68.

141. Oliveri V, Vecchio G. Prochelator strategies for site-selective activation of metal chelators. J Inorg Biochem 2016;162:31-43.

142. Adlard PA, Bush AI. Metals and Alzheimer's disease: how far have we come in the clinic? J Alzheimers Dis 2018;62:1369-79.

143. Bacon B. Iron chelators: choice of agent, dosing, and adverse effects. Waltham: 2020 UpToDate; 29 April 2020. Available from: http://www.uptodate.com

144. Singh YP, Pandey A, Vishwakarma S, Modi G. A review on iron chelators as potential therapeutic agents for the treatment of Alzheimer's and Parkinson's diseases. Mol Divers 2019;23:50926.

145. Kalinowski DS, Richardson DR. The evolution of iron chelators for the treatment of iron overload disease and cancer. Pharmacol Rev 2005;57:547-83.
146. Guo C, Wang T, Zheng W, Shan ZY, Teng WP, Wang ZY. Intranasal deferoxamine reverses iron-induced memory deficits and inhibits amyloidogenic APP processing in a transgenic mouse model of Alzheimer's disease. Neurobiol Aging 2013;34:562-75.

147. Poggiali E, Cassinerio E, Zanaboni L, Cappellini MD. An update on iron chelation therapy. Blood Transfus 2012;10:411-22.

148. Zhang Y, He ML. Deferoxamine enhances alternative activation of microglia and inhibits amyloid beta deposits in APP/PS1 mice. Brain Res 2017;1677:86-92.

149. Hanson LR, Fine JM, Renner DB, Svitak AL, Burns RB, Nguyen $\mathrm{TM}$, et al. Intranasal delivery of deferoxamine reduces spatial memory loss in APP/PS1 mice. Drug Deliv Transl Res 2012;2: 160-8.

150. Guo C, Wang P, Zhong ML, Wang T, Huang XS, Li JY, et al. Deferoxamine inhibits iron induced hippocampal tau phosphorylation in the Alzheimer transgenic mouse brain. Neurochem Int 2013;62:165-72.

151. Crapper McLachlan DR, Dalton AJ, Kruck TP, Bell MY, Smith WL, Kalow W, et al. Intramuscular desferrioxamine in patients with Alzheimer's disease. Lancet. 1991;337:1304-8.

152. Flaten TP. Aluminium as a risk factor in Alzheimer's disease, with emphasis on drinking water. Brain Res Bull 2001;55:187-96.

153. Banerjee P, Sahoo A, Anand S, Bir A, Chakrabarti S. The oral iron chelator, deferasirox, reverses the age-dependent alterations in iron and amyloid-beta homeostasis in rat brain: implications in the therapy of Alzheimer's disease. J Alzheimers Dis 2016;49: 681-93.

154. Kamalinia G, Khodagholi F, Atyabi F, Amini M, Shaerzadeh F, Sharifzadeh M, et al. Enhanced brain delivery of deferasiroxlactoferrin conjugates for iron chelation therapy in neurodegenerative disorders: in vitro and in vivo studies. Mol Pharm 2013;10: 4418-31.

155. Boddaert N, Le Quan Sang KH, Rotig A, Leroy-Willig A, Gallet $\mathrm{S}$, Brunelle F, et al. Selective iron chelation in Friedreich ataxia: biologic and clinical implications. Blood. 2007;110:401-8.

156. Sohn YS, Breuer W, Munnich A, Cabantchik ZI. Redistribution of accumulated cell iron: a modality of chelation with therapeutic implications. Blood. 2008;111:1690-9.

157. Shimmo R, Zetterström Fernaeus S. Amyloid $\beta 25-35$ induced ROS-burst through NADPH oxidase is sensitive to iron chelation in microglial Bv2 cells.Brain Res. 2015 Dec 10;1629:282-90. https://doi.org/10.1016/j.brainres.2015.09.034. Epub 2015 Oct 23

158. Molina-Holgado F, Gaeta A, Francis PT, Williams RJ, Hider RC. Neuroprotective actions of deferiprone in cultured cortical neurones and SHSY-5Y cells. J Neurochem 2008;105:2466-76.

159. Prasanthi JR, Schrag M, Dasari B, Marwarha G, Dickson A, Kirsch WM, et al. Deferiprone reduces amyloid-beta and tau phosphorylation levels but not reactive oxygen species generation in hippocampus of rabbits fed a cholesterol-enriched diet. J Alzheimers Dis 2012;30:167-82.

160. Pandolfo M, Arpa J, Delatycki MB, Le Quan Sang KH, Mariotti C, Munnich A, et al. Deferiprone in Friedreich ataxia: a 6-month randomized controlled trial. Ann Neurol 2014;76:509-21.

161. Abbruzzese G, Cossu G, Balocco M, Marchese R, Murgia D, Melis M, et al. A pilot trial of deferiprone for neurodegeneration with brain iron accumulation. Haematologica. 2011;96:1708-11.

162. Ayton S, Lei P, Bush AI. Biometals and their therapeutic implications in Alzheimer's disease. Neurotherapeutics 2015;12:109-20.

163. Cherny RA, Atwood CS, Xilinas ME, Gray DN, Jones WD, McLean CA, et al. Treatment with a copper-zinc chelator markedly and rapidly inhibits beta-amyloid accumulation in Alzheimer's disease transgenic mice. Neuron. 2001;30:665-76.

164. Tahmasebinia F, Emadi S. Effect of metal chelators on the aggregation of beta-amyloid peptides in the presence of copper and iron. Biometals. 2017;30:285-93. 
165. Ritchie CW, Bush AI, Mackinnon A, Macfarlane S, Mastwyk M, MacGregor L, et al. Metal-protein attenuation with iodochlorhydroxyquin (clioquinol) targeting Abeta amyloid deposition and toxicity in Alzheimer disease: a pilot phase 2 clinical trial. Arch Neurol 2003;60:1685-91.

166. Xie S, Chen J, Li X, Su T, Wang Y, Wang Z, et al. Synthesis and evaluation of selegiline derivatives as monoamine oxidase inhibitor, antioxidant and metal chelator against Alzheimer's disease. Bioorg Med Chem 2015;23:3722-9.

167. Mi Z, Gan B, Yu S, Guo J, Zhang C, Jiang X, et al. Dual-target anti-Alzheimer's disease agents with both iron ion chelating and monoamine oxidase-B inhibitory activity. J Enzyme Inhib Med Chem 2019;34:1489-97.

168. Youdim MBH. Monoamine oxidase inhibitors, and iron chelators in depressive illness and neurodegenerative diseases. J Neural Transm (Vienna) 2018;125:1719-33.

169. Amit T, Bar-Am O, Mechlovich D, Kupershmidt L, Youdim $\mathrm{MBH}$, Weinreb O. The novel multitarget iron chelating and propargylamine drug M30 affects APP regulation and processing activities in Alzheimer's disease models. Neuropharmacology. 2017;123:359-67.

170. Kupershmidt L, Amit T, Bar-Am O, Youdim MB, Weinreb O. The novel multi-target iron chelating-radical scavenging compound M30 possesses beneficial effects on major hallmarks of Alzheimer's disease. Antioxid Redox Signal 2012;17:860-77.

171. Gaeta A, Molina-Holgado F, Kong XL, Salvage S, Fakih S, Francis PT, et al. Synthesis, physical-chemical characterisation and biological evaluation of novel 2-amido-3-hydroxypyridin$4(1 \mathrm{H})$-ones: iron chelators with the potential for treating Alzheimer's disease. Bioorg Med Chem 2011;19:1285-97.

172. Cong L, Dong X, Wang Y, Deng Y, Li B, Dai R. On the role of synthesized hydroxylated chalcones as dual functional amyloidbeta aggregation and ferroptosis inhibitors for potential treatment of Alzheimer's disease. Eur J Med Chem 2019;166:11-21.

173. Zheng H, Youdim MB, Fridkin M. Selective acetylcholinesterase inhibitor activated by acetylcholinesterase releases an active chelator with neurorescuing and anti-amyloid activities. ACS Chem Neurosci 2010;1:737-46.

174. Chand K, Alsoghier HM, Chaves S, Santos MA. Tacrine(hydroxybenzoyl-pyridone) hybrids as potential multifunctional anti-Alzheimer's agents: AChE inhibition, antioxidant activity and metal chelating capacity. J Inorg Biochem 2016;163:266-77.

175. Chand K, Rajeshwari, Candeias E, Cardoso SM, Chaves S, Santos MA. Tacrine-deferiprone hybrids as multi-target-directed metal chelators against Alzheimer's disease: a two-in-one drug. Metallomics. 2018;10:1460-75.

176. Barbosa FAR, Canto RFS, Saba S, Rafique J, Braga AL. Synthesis and evaluation of dihydropyrimidinone-derived selenoesters as multi-targeted directed compounds against Alzheimer's disease. Bioorg Med Chem 2016;24:5762-70.

177. Mohamed T, Mann M, Rao P. Application of quinazoline and pyrido[3,2-d]pyrimidine templates to design multi-targeting agents in Alzheimer's disease. RSC Adv 2017;7:22360-8.
178. Hiremathad A, Chand K, Tolayan L, Rajeshwari, Keri RS, Esteves $\mathrm{AR}$, et al. Hydroxypyridinone-benzofuran hybrids with potential protective roles for Alzheimer s disease therapy. J Inorg Biochem 2018;179:82-96.

179. Nunes A, Marques SM, Quintanova C, Silva DF, Cardoso SM, Chaves S, et al. Multifunctional iron-chelators with protective roles against neurodegenerative diseases. Dalton Trans. 2013;42: 6058-73.

180. Jiao Y, Wilkinson Jt, Christine Pietsch E, Buss JL, Wang W, Planalp R, et al. Iron chelation in the biological activity of curcumin. Free Radic Biol Med 2006;40:1152-60.

181. Duarte Y, Fonseca A, Gutierrez M, Adasme-Carreno F, MunozGutierrez C, Alzate-Morales J, et al. Novel coumarin-quinoline hybrids: design of multitarget compounds for Alzheimer's disease. ChemistrySelect. 2019;4:551-8.

182. Zhang C, Yang K, Yu S, Su J, Yuan S, Han J, et al. Design, synthesis and biological evaluation of hydroxypyridinonecoumarin hybrids as multimodal monoamine oxidase B inhibitors and iron chelates against Alzheimer's disease. Eur J Med Chem 2019;180:367-82.

183. Sheng R, Tang L, Jiang L, Hong L, Shi Y, Zhou N, et al. Novel 1phenyl-3-hydroxy-4-pyridinone derivatives as multifunctional agents for the therapy of Alzheimer's disease. ACS Chem Neurosci 2016;7:69-81.

184. Southon A, Szostak K, Acevedo KM, Dent KA, Volitakis I, Belaidi AA, et al. $\mathrm{Cu}$ (II) (atsm) inhibits ferroptosis: implications for treatment of neurodegenerative disease. Br J Pharmacol 2020;177:656-67.

185. Evans A, Rowe D, Lee W, Noel K, Rosenfeld CS. Preliminary evidence of CuATSM treatment benefit in Parkinson's disesase. XXIV World Congress on Parkinson's Disease and Related Disorders; 16-19 June 2019; Montreal, Canada 2019.

186. Rowe D, Mathers S, Smith G, Widebank E, Rogers M-L, Noel K, et al. Modification of ALS disease progression in a phase 1 trial of CuATSM. Amyotrophic Lateral Sclerosis and Frontotemporal Dementia 2018;19:280-1

187. Donnelly PS, Caragounis A, Du T, Laughton KM, Volitakis I, Cherny RA, et al. Selective intracellular release of copper and zinc ions from bis(thiosemicarbazonato) complexes reduces levels of Alzheimer disease amyloid-beta peptide. J Biol Chem 2008;283: 4568-77.

188. Palanimuthu D, Wu Z, Jansson PJ, Braidy N, Bernhardt PV, Richardson DR, et al. Novel chelators based on adamantanederived semicarbazones and hydrazones that target multiple hallmarks of Alzheimer's disease. Dalton Trans. 2018;47:7190-205.

189. Palanimuthu D, Poon R, Sahni S, Anjum R, Hibbs D, Lin HY, et al. A novel class of thiosemicarbazones show multi-functional activity for the treatment of Alzheimer's disease. Eur J Med Chem 2017;139:612-32.

Publisher's Note Springer Nature remains neutral with regard to jurisdictional claims in published maps and institutional affiliations. 